\title{
Comparison of Damage Path Predictions for Composite Laminates by Explicit and Standard Finite Element Analysis Tools
}

\author{
Philip B. Bogert ${ }^{1}$ \\ NASA Langley Research Center \\ Hampton, VA 23681 \\ Arunkumar Satyanarayana ${ }^{2}$ \\ Swales Aerospace \\ Hampton, VA 23681 \\ Prasad B. Chunchu ${ }^{3}$ \\ Eagle Aeronautics \\ Hampton, VA 23669
}

\begin{abstract}
Splitting, ultimate failure load and the damage path in center notched composite specimens subjected to in-plane tension loading are predicted using progressive failure analysis methodology. A 2-D Hashin-Rotem failure criterion is used in determining intra-laminar fiber and matrix failures. This progressive failure methodology has been implemented in the Abaqus/Explicit and Abaqus/Standard finite element codes through user written subroutines "VUMAT" and "USDFLD" respectively. A 2-D finite element model is used for predicting the intra-laminar damages. Analysis results obtained from the Abaqus/Explicit and Abaqus/Standard code show good agreement with experimental results. The importance of modeling delamination in progressive failure analysis methodology is recognized for future studies. The use of an explicit integration dynamics code for simple specimen geometry and static loading establishes a foundation for future analyses where complex loading and nonlinear dynamic interactions of damage and structure will necessitate it.
\end{abstract}

\section{Introduction}

The drive to achieve high strength and stiffness-to-weight ratio has propelled composite materials to the forefront among other structural materials. As the motivation for using composite materials in aerospace structures is increasing, researchers are trying to understand the damage mechanisms under tensile, compressive, impact, pressure and several combined load conditions. Even though research has been performed to predict linear and nonlinear response of composite structures, many researchers are still trying to gain a greater understanding of the damage mechanisms, damage modes and damage propagation. Progressive failure analysis methodology implemented in nonlinear finite element analysis codes has been one of the approaches adopted by researchers in recent

\footnotetext{
1 Aerospace Engineer, Mechanics of Structures and Materials Branch

${ }^{2,3}$ Senior Research Engineer, Member AIAA.
} 
years to try to simulate the failure modes in composite structures and eventually predict the damage paths and failure loads.

The damage in composite structures is generally a combination of matrix cracking, fiber breakage in tension and compression, and delamination. The first two damage modes, matrix cracking and fiber breakage in tension and compression, are called intra-laminar damage and the third damage mode, delamination, is called inter-laminar damage. These damage modes can lead to significant strength reduction in the postdamage performance of the structure.

Numerous finite element analyses using progressive failure analysis methodology have been performed to predict the failure load and contact forces for specimens subjected to tensile and impact loads respectively. However, few authors have gone to the extent of predicting damage paths representing complete failure of the specimens. In this regard, a literature survey on progressive failure analysis methodology, encompassing various loading conditions and analysis types was performed and selected results are presented below.

A significant amount of early work in establishing PFA methods was performed by Chang and his associates. This included tensile and compressively loaded coupons with notches and holes. Failure load and damage modes were predicted for laminates containing holes under compressive loading conditions. Stacking sequence and clustering of 0 and 90 degree fibers was also investigated [1,2]. Tan also contributed to the early PFA methods development by deriving simplified damaged ply constitutive relationships. When used in a progressive failure analysis for orthotropic laminates with holes loaded in tension, failure load and damage accumulation is predicted. Tan also studied the effect of mesh size and load increment on ultimate failure load [3]. Intralaminar damage modeling has been considered to study matrix damage and fiber damage under impact loading conditions [4-9]. In their effort to predict the onset of fiber and matrix damage, many of the authors have used Hashin's failure criteria $[10,11]$. The progressive failure analysis methodology has been implemented in the COMET [12] nonlinear static analysis code to predict failure load and the damage path in a composite laminate under static rail-shear loading [13]. In this study, even though the damaged area has been predicted, it is not clear whether the damaged area contains $100 \%$ failed plies. Further, the capabilities of this code to predict damage propagation are not clear. Wang et al. [14] tried to predict damage progression in a tension loaded stiffened composite panel with a discrete source of damage. Even though the prediction of the failure load of the panel is very close to the experimentally determined load, the work does not demonstrate the adequacy of this code to predict damage propagation. McGowan, et al., [15] have used the Abaqus/Standard code to predict damage path and the failure load of a notched stitched composite plate under static uni-axial compression and to demonstrate that progressive failure analysis can be used to predict failure load. It was concluded that the prediction of the complete damage path requires additional study. Predictions of the failure load and damage path of extension-shear-coupled stiffened composite panels under compressive load, have been successfully performed by Baker [16], using progressive failure methodology in the STAGS [17] nonlinear finite element code. More 
recently, Qing, Chang and Starnes used an intra-laminar progressive failure algorithm in conjunction with Abaqus to predict the damage patterns and tensile failure loads of notched laminates with co-cured reinforcing strips. Analytical failure loads agreed well with test data for a variety of notch sizes and reinforcing strip thicknesses when the failure mode was dominated by self-similar damage progression. When thicker reinforcing strips were used, splitting occurred when the damage reached the strip. Splitting was accompanied by delamination of the strip leading to a $12 \%$ over-prediction in failure load. This result supports the inclusion of inter-laminar effects in future code development. From the data presented, only about one third of the experimentally observed damage path was predicted near peak loading [18]. An alternative approach was adopted by Tay, Liu and Tan where the element forces are degraded rather that the stiffness matrix when a strain invariant theory predicts damage [19]. This method is called the SIFT-EFM approach (Strain Invariant Failure Theory-Element Failure Method) and is used by the authors to predict damage path.

The majority of the studies implemented progressive failure analysis methodology using either static or implicit integration scheme dynamic finite element analysis codes to predict intra-laminar damages. From the earlier works, it can be observed that the simulations often stopped prematurely due to convergence difficulties, when a relatively small percentage of elements failed completely, thereby becoming unable to predict the complete damage path.

Hence, this paper utilizes the progressive failure analysis methodology in an explicit integration dynamic finite element code to predict damage modes, damage path and failure loads in center notched tensile specimens loaded under static conditions. One of the prime motivating factors in using an explicit integration dynamics code, though unusual for analyzing static problems is that once the damage starts propagating unstably, the problem could become dynamic locally, even if not globally. Under this condition, the damage path may change its direction due to changes in the local loading paths, which the static code may not be able to capture during the rapidly propagating damage state. Therefore in the present study, both the Abaqus/Explicit and Abaqus/Standard codes have been used to predict the damage modes of statically loaded tensile specimens with a center notch.

The objective is to predict failure load and the associated damage path up to failure for different laminate sequences, exhibiting varying damage modes, with a progressive failure algorithm. To achieve this, numerical and experimental studies were performed on flat center notched axially loaded specimens. The numerical studies utilized the Abaqus/Standard and Abaqus/Explicit codes with user written subroutines containing the progressive failure algorithms. Comparisons were then made with the experimental results, and the adequacy of the numerical approach was evaluated. 


\section{Modeling Damage Paths}

$\underline{\text { Nonlinear Analysis }}$

The procedures for predicting the growth of the damage path are developed using the progressive failure analysis methodology implemented within the Abaqus/Explicit and Abaqus/Standard dynamic finite element analysis code, using the user written subroutines VUMAT [20] and USDFLD [9] respectively. Geometric and material nonlinearity are included in both the codes. The geometric nonlinearity is due to large displacement and moderate rotation kinematics. Material nonlinear behavior is associated with degradation of the material properties of the plies to simulate intralaminar failures. The progressive failure analysis methodology generally consists of three steps: a) calculating the stress state from the nonlinear analysis, b) substituting these stresses, at various "material" points through the thickness of each element, into a failure criterion to evaluate the element's integrity and c) degrading the material stiffness in the failed elements to represent damage. The implementation of the above steps in the standard and explicit codes is explained below.

The Abaqus/Standard nonlinear analysis code solves a static or dynamic nonlinear system of equations using the Newton-Raphson method. The static nonlinear system of equations is represented in equation (1) as:

$[\mathrm{K}(x)] x=\mathrm{F}$

Where $K$ is the stiffness matrix, $x$ is the displacement vector and $F$ is the applied load vector. Once the stress state is determined the damage state in the material point is evaluated through the failure criterion. Based on the failure mode, the material properties are reduced according to the degradation model and then a new stiffness matrix is computed. The equilibrium is re-established between the external force vector and the internal loads by repeating the nonlinear analysis at the current load step. Once the equilibrium is established, the nonlinear analysis advances to the next load step. In the case of implicit dynamic analysis the equations of motion are directly integrated but, as with static analysis, the reformed stiffness matrix, and in some dynamic analysis cases the mass matrix as well, must be inverted at each step.

Unlike Abaqus/Standard, the Abaqus/Explicit code solves a set of dynamic equations in an iterative method. Even though the Abaqus/Explicit code is intended to solve highly dynamic problems, it can also be effectively used to solve quasi-static problems. Again, in the case of predicting damage paths in composite structures, one needs to degrade material properties to represent failure. This causes the material stiffness to be reduced to almost zero and eventually leads to the previously mentioned convergence difficulties in the Abaqus/Standard static and implicit integration dynamic codes. However, Abaqus/Explicit uses a central difference rule to integrate the equations of motion through time at the element level, using kinematic conditions at one increment to calculate the kinematic conditions at the next increment. At the beginning of the 
increment the code solves a set of dynamic equilibrium equations, represented in equation (2)

$M \ddot{x}=F-[K(x)] x$

The above equation states that the nodal mass matrix, $M$, times the nodal accelerations, $\ddot{x}$, equals the total nodal forces, which are the difference between the externally applied loads and the internal forces at the element level. As the explicit procedure uses a diagonal mass matrix, solving for acceleration in the equation (2) is trivial and does not involve solving the simultaneous equations associated with mass and stiffness matrix inversion. Once the accelerations are calculated, the velocities and displacements are computed by integrating the accelerations explicitly through time. From the element calculations, the element stresses and consequently, the internal forces are computed. These procedures have been well established [20,21].

\section{$\underline{\text { Failure Criterion }}$}

The second step in the progressive failure analysis is to calculate damage state from the element stresses. The Hashin-Rotem criterion [11] has been used in this study to predict intra-laminar damage modes such as fiber failures and matrix failures. The intra-laminar failure modes considered are

a. Fiber failure in tension and compression,

b. Matrix-cracking in tension and compression,

The stresses are computed in the principal material directions for each ply orientation and are used in the unidirectional failure criteria. The failure criteria are expressed in terms of the planar stresses $\sigma_{i j}$, the fiber direction and transverse direction strengths, $\mathrm{X}$ and $\mathrm{Y}$, respectively, and the shear allowable $S$. The in-plane stresses are $\sigma_{11}$, $\sigma_{22}$, and $\tau_{12}$. The strengths parallel and perpendicular to the fiber direction are denoted as $X$ and $Y$, respectively, and the in-plane shear strength is $S_{12}$. The subscripts 'c' and ' $\mathrm{t}$ ' denote compression and tension.

Fiber failure in tension and compression is considered to occur independently of the other stress components in the Hashin-Rotem failure criteria. The fiber failure index, $e_{\mathrm{f}}$ is defined as,

$$
\begin{aligned}
& e_{f}^{2}=\left(\frac{\sigma_{11}}{X_{t}}\right) \text { for } \sigma_{11}>0 \\
& e_{f}^{2}=\left(\frac{\sigma_{11}}{X_{c}}\right) \text { for } \sigma_{11}<0
\end{aligned}
$$


The failure index, $e_{\mathrm{m}}$, for matrix cracking is,

$$
\begin{aligned}
& e_{m}^{2}=\left(\frac{\sigma_{22}}{Y_{t}}\right)^{2}+\left(\frac{\tau_{12}}{S_{12}}\right)^{2}, \quad \sigma_{22}>0 \\
& e_{m}^{2}=\left(\frac{\sigma_{22}}{Y_{c}}\right)^{2}+\left(\frac{\tau_{12}}{S_{12}}\right)^{2}, \quad \sigma_{22}<0
\end{aligned}
$$

\section{$\underline{\text { Material Degradation Models }}$}

The third and final step in the progressive failure analysis is to apply the material degradation model to the failed material points. The material properties are degraded based upon the damage mode. The progressive failure analysis in Abaqus/Explicit is implemented using the user-written subroutine VUMAT [20]. The VUMAT subroutine is invoked at each material point of an element to evaluate the failure criterion. When failure is detected, the degradation model is applied accordingly. In the current work, certain stresses are set to zero, according to the degradation model presented in Table 1, depending on the damage mode that has occurred. The DELETE parameter within the user-written subroutine VUMAT deletes a material point by prescribing zero stresses and a zero strain increment to the material point. Once a material point has been flagged as deleted, it cannot be reactivated. The Abaqus/Explicit code will check for elements where all of the material points have been flagged as deleted and remove these elements from further computations. The output variable STATUS [20] will indicate if an element is active or not. A value of 1.0 for the STATUS output variable indicates an active element, and a value of zero indicates a deactivated or deleted element. In the present analysis, the internal state variable, $d_{f}$, which represents the fiber failure damage mode is assigned to the DELETE parameter. Hence the damage path prediction is achieved by deleting (or eroding) an element when all of the material points within the element have failed in the fiber failure mode or when any of the in-plane strain components reach a value higher than 100,000 micro strain. Since no global matrix inversion is performed, this procedure does not lead to the matrix singularities that limit the static and implicit dynamic methods.

In contrast with Abaqus/Explicit, the degradation model adopted in Abaqus/Standard is given in Table 2. In this model, the material stiffness $\mathrm{E}_{11}, \mathrm{E}_{22}$ and $\mathrm{G}_{12}$ are instantaneously reduced to $1000 \mathrm{psi}$ and $v_{12}$ is reduced to 0.01 based upon the failure mode.

\section{Experimental Description}

The geometric description of the center notched composite laminate specimens used in the current investigation is shown in Figure 1. The specimens have a test section of 6 in. $x 3$ in. The specimens have 2.75 in. tab section on either end, which fits into the grip of a servo-hydraulic testing machine. The center notch has dimensions of $0.75 \mathrm{in} . \mathrm{x}$ $0.09375 \mathrm{in}$. The notch was machined using a titanium coated carbide milling tool. Using

a diamond coated pin as a deburring tool, the free edges and tips of the notch were 
cleaned. The specimens were made of T800/3900-2, a toughened epoxy CFRP composite material, whose stiffness properties and strengths are given in Table 3 [22]. The strain gage locations on the specimens are shown in Figure 2. All are axial gages. The strain gage on the notch tip is a type EA-06-070LC-350 and CEA-06-187 UW-350 type gages are used for other locations. The laminate sequences and their corresponding thicknesses are defined in Table 4.

The percentage of $0^{\circ}$ plies in each laminate sequences was determined based upon earlier experimental works, where the ply percentages were typically designed to generate different types of damage paths around the notch tips. Laminate sequence-1, which consists of $100 \% 0^{\circ}$ plies, was expected to fail initially by splitting (crack propagating perpendicular to the notch direction) due to shear stress in the matrix and ultimately by fiber failure due to axial stress in the fibers of the remaining ligaments. Laminate sequence-2, which has $40 \% 0^{\circ}$ plies, was expected to fail predominantly due to fiber breakage in all the plies except the $90^{\circ}$ plies. Laminate sequence- 3 , which contains $58 \% 00^{\circ}$ plies was expected to fail initially by splitting at the notch tips and ultimately fail due to self-similar crack growth in the remaining ligaments. Here, the term ultimate failure refers to the total separation of the specimen into two or more pieces such that it has no load bearing capacity. One specimen for laminate sequence- 1 and three specimens for laminate sequences- 2 and -3 were tested.

The specimens were statically tensile loaded at room temperature under displacement control at a rate of 0.005 inches/minute. Test data was acquired every half second. A Visual Image Correlation (VIC) technique was used to measure the full-field 3-D deformation of the specimens [23]. This technique requires that a random speckle pattern be applied to one surface of the specimen, which is monitored with two slightly offset cameras during the duration of the test. The images from the cameras, that were taken every 5 seconds, were then compared by the data reduction software to determine the speckle pattern movement in space. These measurements provide a quantitative full field deformation pattern. In the case of laminate sequence-1, the specimen was loaded up to $25,000 \mathrm{lbs}$., well beyond the splitting load but short of ultimate failure load of the specimen. For laminate sequence-2, the specimens were loaded all the way to ultimate failure. However, in laminate sequence-3, one specimen was loaded until the split occurred and two specimens were loaded all the way to ultimate failure. The results presented for laminate sequence-3, are for the specimen which was loaded until splitting occurred, as the results for the other two specimens were very similar. Two extensometers of 4 inches span length were installed on the two vertical longitudinal edges of the specimens, with the ends equidistant from the horizontal notch line. This provided the direct measurement of the elongation throughout the loading profile.

\section{$\underline{\text { Finite Element Model Description }}$}

The finite element model, which is shown in Figure 3, consists of only the test section which is 3.0 inches wide and 6.0 inches long with the center notch of size 0.75 inches wide by 0.09376 inches high. The finite element model of these specimens was developed using 2-D 4 node quadrilateral elements whose size is approximately 0.06 
inches by 0.06 inches. One of the shorter edges is fixed in all the translational and rotational degrees of freedom about the $\mathrm{x}, \mathrm{y}$ and $\mathrm{z}$ directions. The other shorter edge is fixed in the $\mathrm{y}$ and $\mathrm{z}$ translational and $\mathrm{x}, \mathrm{y}$ and $\mathrm{z}$ rotational degrees of freedom. The two long edges are free. The finite element type used in the progressive failure analyses is the Abaqus S4R and the 2-D model consists of 5264 nodes and 5100 elements. Progressive failure analyses (PFA) of the finite element models were performed using the Abaqus/Standard and the Abaqus/Explicit codes.

In the Abaqus/Standard static analysis enforced end displacements of 0.05 inches, 0.035 inches and 0.065 inches were applied gradually in the longitudinal direction (Xdirection) for laminate sequences-1, -2 and -3 respectively. $0.1 \%$ of the total displacement was chosen as the initial load step and the same step was maintained until the end of the simulation. In case of Abaqus/Explicit, the displacements of 0.05 inches, 0.035 inches and 0.065 inches were applied to the model over periods of $0.01 \mathrm{sec}, 0.007$ sec and 0.013 seconds respectively. During the entire simulation, the kinetic energy of the model was checked to ascertain that it did not exceed 5\% of the total strain energy of the model. This was necessary to ensure that significant dynamic effects were not introduced while using the fictitiously small total loading time required for computational efficiency.

A finite element mesh iterative study was conducted to determine the optimum mesh size. As observed in both the current study and by several other studies [24], a very fine mesh at the notch tip will lead to a lower failure load and a coarse mesh to a higher failure load. Since the purpose of this study was to predict failure load, damage modes and damage path, a mesh size that yielded good correlation with the experimental results for laminate sequence-1 was first determined and then used in the analyses of all other laminate sequences. This turned out to be an element edge size of $0.06 \mathrm{in}$. The mesh is shown in Figure 3.

\section{$\underline{\text { Results and Discussion }}$}

The results obtained from the progressive failure analyses of the center notch tension specimens, using Abaqus/Standard, Abaqus/Explicit, and the experimental data are presented in Figures 4 to 28. The strain gages mounted on the specimens are designated as Sg-1, Sg-2, Sg-3 and Sg-4 and their locations are given in Figure 2. Table 5 presents the failure loads of the specimens representing laminate sequences-1, 2 and 3 .

\section{$\underline{\text { Laminate Sequence }-1}$}

Figure 4 presents the load-elongation data of the specimen with laminate sequence-1. It can be noticed from the figure that the stiffness of the specimen changes slightly when its elongation in the loading direction reaches around 0.007 inches. The change in stiffness is due to matrix damage, which starts from the notch tips and propagates perpendicular to the notch in both directions until it reaches the tabbed end. This mode of damage is referred to as splitting and occurs due to the domination of the in-plane shear stress to shear strength ratio at the notch tips (dominant as compared with 
the normal stress to normal strength ratio at the tips). The predicted load at which the splitting occurred is reported in Table 5. All three of the loads, which were obtained from Abaqus/Explicit, Abaqus/Standard and the experiment, are in good agreement. Figures 5 to 7 report the strain data obtained at the far field, near the notch tip and at the notch tip. It can be noticed from these plots that the strain values obtained by Abaqus/Explicit and Abaqus/Standard are in reasonable agreement with the experimental data. Figures 8 to 10 show the damage path predictions from Abaqus/Explicit, Abaqus/Standard and the experiment. The very fine matrix cracks, which appeared in the test specimen, were hard to see with the naked eye. However a C-Scan picture of this specimen, which clearly reveals the crack path is shown in Figure 10. From this figure it can be noticed that the cracks on either side of the notch tips grew equally to the tabs. The specimen was not loaded to final failure, as the purpose of this test was to predict the onset of splitting and the extent of damage due to shear stress.

\section{$\underline{\text { Laminate Sequence }-2}$}

Three specimens of this laminate sequence were tested and the average failure load is reported in Table 5 along with the percent difference from the experimental failure load. The failure loads predicted by Abaqus/Explicit and Abaqus/Standard are in good agreement with the experimentally determined failure load. Figure 11 shows the loadelongation curve for the specimen representing laminate sequence-2. Figures 12 to 14 show the strain data at the far field, near the notch tip and at the notch tip. The strain values are in good agreement with the experimental data except for strain gage 4 , which is located almost on the notch tip. From Figure 14 it can be seen that the strain obtained experimentally remains linear within a short load range and then becomes nonlinear as the specimen is loaded further. This behavior could be attributed to the presence of interlaminar stress at the notch free edges. It is well established that the angled and cross plies in a laminate produce inter-laminar stresses, which is the case in laminate sequence- 2 . When these stresses reach the failure limit of the material, inter-laminar matrix damage occurs and causes the adjacent plies to debond. Furthermore, since the strain predictions at the notch tip for laminate sequence-1 (which was a uni-directional laminate) matched very well with the experimental strains, it could be concluded with some degree of confidence that the inter-laminar stress at the free edges would have caused the strain at the notch tips to behave nonlinearly in laminate sequence- 2 . Since the present progressive failure analysis methodology does not account of these damages, it is not possible to predict strains accurately in these highly nonlinear regions around the notch.

Figures 15 and 16 show the damage path predictions from the Abaqus/Explicit and Abaqus/Standard analyses for all the layer directions. Since the dominant mode of damage for this type of laminate sequence is fiber breakage, only the fiber failure predictions are shown in Figures 15 and 16. Figure 17 shows the damage path of one of the test specimens. From Figure 15, it can be observed that the fiber breakage path in $45^{\circ}, 0^{\circ}$ and $-45^{\circ}$ plies are similar in nature. However, the $90^{\circ}$ ply shows some tensile fiber breakages, which are unlikely for tensile loading perpendicular to these fibers. This type of prediction, which occurs only near final failure, could be attributed to the fact that in Abaqus /Explicit, when the fiber fails, the material properties in failed elements are 
degraded instantaneously to zero. The instantaneous degradation of properties has been observed to excite some arbitrary stress waves in the model, which would thereby develop premature local failure stresses in some of the elements in the $90^{\circ}$ ply. In Figure 16 , it can be seen that the fiber breakage pattern in all the plies, predicted by Abaqus/Standard, is only slightly different from the pattern predicted by Abaqus/Explicit. However, closer investigation reveals that in the $90^{\circ}$ ply the fibers failed due to compressive stress in the static analysis. This is also unlikely with tensile loading perpendicular to the fibers. This calls for further investigation of the PFA steps adopted in the Abaqus/Standard analysis to determine whether the numerical problems associated with near "zero" damage zone stiffness after element degradation could be causing the compressive failure predictions. The dominant matrix damage mode in the $90^{\circ}$ ply was correctly predicted. Figure 17 shows the actual damage in the failed test specimen. From this picture it can be noticed that the crack starts propagating in a self-similar fashion from the notch tips for a small distance and then changes direction. When the crack changed direction, by a small angle, on one side of the notch tip, it continued to grow in the changed direction until failure. However on the other side of the notch tip, it can be noticed that the crack turned one more time slightly towards the normal line to the notch. The authors feel that one possible reason for the crack changing direction as it grew could be the uneven loading of the specimen which was observed in the in-plane displacement plots generated by VIC3D as shown in Figure 18.

\section{Laminate Sequence -3}

Figure 19 shows the load-elongation curve for a laminate sequence- 3 specimen. The curves generated by Abaqus/Explicit and Abaqus/Standard predict splitting at around $18000 \mathrm{lbs}$. However the splitting was first noticed in specimen at around $25840 \mathrm{lbs}$. The prediction of the splitting load by Abaqus/Explicit and Abaqus/Standard is significantly lower than that measured in the experiment. Figures 20 to 22 show the strain values at the far field, and near the notch tip. From these plots is can be noticed that the strains predicted by Abaqus/Explicit and Abaqus/Standard match each other through most of the loading range and match the experimental strains reasonably well until the predicted splitting load. However, in addition to under predicting the measured splitting load, both analyses also under predicted the ultimate failure load at around $31000 \mathrm{lbs}$., compared to the measured ultimate failure load of around $39000 \mathrm{lbs}$. Figures 23 to 25 show the crack path predicted by Abaqus/Explicit, Abaqus/Standard and the actual path observed in the specimen. Both of the analytical tools predicted "H" type splitting (damage progression perpendicular to the notch tips both above and below each tip) where a " $Z$ " type splitting (damage progression perpendicular to the notch tips, but only above one tip and below the other tip) was observed in the failed specimen as shown in the C-Scan picture presented in Figure 26. Delaminations were also observed along the crack path and ultimately the specimens failed with a self-similar crack growth starting from the notch tips as shown in Figure 27. The reason for "Z" type splitting could be attributed to the non-uniform loading of the tabbed ends which was revealed in the in-plane displacement plot generated by VIC3D as shown in Figure 28. From figures 26 and 27 it can be noticed that delamination is one of the dominant modes of failure for this laminate sequence. Delamination can dissipate energy thereby causing the specimen to fail at a 
higher load. Since the analytical tools (Abaqus/Explicit \& Abaqus/Standard) used in the current analyses do not include delamination modeling capability, predicting the failure load and the damage path accurately for these types of laminate sequences becomes impossible.

\section{$\underline{\text { Conclusions }}$}

The ability to predict the damage modes, damage path and the failure loads of statically loaded center notch tensile specimens, where delamination is not a significant failure mode, has been successfully demonstrated. The experimentally observed damage paths, such as splitting in case of the laminate sequence-1 specimens and self-similar crack growth in the laminate sequence- 2 specimens, have been accurately predicted by Abaqus/Explicit and Abaqus/Standard. Additionally, the measured strains at the far field and near the notch tips have been predicted fairly accurately through the entire loading range. Since the present progressive failure analysis tools do not have the capability to model inter-laminar damages such as delamination, it is recognized that this damage mode needs to be included in order to predict the damage path and the failure load accurately for specimens like laminate sequence- 3 , and for other laminate sequences.

Concerning the use of a dynamic analysis explicit integration code for this simple geometry and static loading, it proved to be more complicated than was necessary. The static analysis was much more computationally efficient and captured the damage path accurately. This was in spite of concerns about the adverse effects of matrix singularities that we have seen in other cases where static or implicit dynamic methods were used. The authors feel that the ability of the static analysis to predict the complete damage path may have been attributed to the simple geometry and failure mechanisms that involved a very small percentage of the total elements in the model.

\section{$\underline{\text { References }}$}

1. Chang, F. K., Chang, K. Y., "A Progressive Damage Model for Laminated Composites Containing Stress Concentrations", Journal of Composite Materials, Vol. 21, September 1987.

2. Chang, F. K., Lessard, L., "Damage Tolerance of Laminated Composites Containing an Open Hole and Subjected to Compressive Loadings: Part I - Analysis", Journal of Composite Materials, Vol. 25, January 1991.

3. Tan, S., "A Progressive Failure Model for Composite Laminates Containing Openings", Journal of Composite Materials, Vol. 25, May 1991.

4. Gama, B. A., Xiao, J. R., Hague, M. J., Yen, C. F., and Gillespie, J. W., Jr., "Experimental and Numerical Investigations on Damage and Delamination in Thick Plain Weave S-2 Glass Composites Under Quasi-Static Punch Shear Loading," $18^{\text {th }}$ Annual Technical Conference of American Society for Composites, University of Florida, Gainesville, FL, October 19-22, 2003.

5. Davies, G. A. O., and Zhang, X., "Impact Damage Prediction in Carbon Composite Structures," International Journal of Impact Engineering, Vol. 16, No. 1, 1995, pp. 149-170. 
6. Yen, C. F., and Cassin, T., "Progressive Failure Analysis of Thin Walled Composite Tubes under Low Energy Impact," Proceedings of the AIAA/ASME/ASCE/AHS/ASC $39^{\text {th }}$ Structures, Structural Dynamics \& Materials Conference, April 20-23, Long Beach, CA, AIAA paper No. 98-1742, pp. 363-371, 1998.

7. Minnetyan, L., and Abdi, F., "Dynamic Impact Loading Damage Propagation in Composite Structures," Proceedings of the AIAA/ASME/ASCE/AHS/ASC $45^{\text {th }}$ Structures, Structural Dynamics \& Materials Conference, April 19-22, Palm Springs, CA, AIAA paper No. 2004-1688, 2004.

8. Yen, C.F., "Analysis of Impact Damage Progression in Composite Structures," Proceedings of the $5^{\text {th }}$ LS-DYNA User Conference, Southfield, Michigan, USA, September 21-22, 1998.

9. Ambur, D. R., Jaunky, N., and Davila, C. G., "Progressive Failure of Composites Laminates using LaRC02 Failure Criteria," Proceedings of the AIAA/ASME/ASCE/AHS/ASC 45th Structures, Structural Dynamics, and Materials Conference, April 19-22, Palm Springs, CA, AIAA paper No. 2004-1595-CP, 2004.

10. Hashin, Z., "Failure Criteria for Unidirectional Fiber Composites," Journal of Applied Mechanics, Vol. 47, 1980, pp. 329-334.

11. Hashin, Z., and Rotem, A., "A Fatigue Failure Criterion for Fiber Reinforced Composite Materials", Journal of Composite Materials, Vol. 7, October 1973, pp. 448-464.

12. Lo, D. C., T. W. Coats, C. E. Harris \& D. H. Allen, "Progressive Damage Analysis of Laminated Composite (PDALC) (A Computational Model Implemented in the NASA COMET Finite ELEMENT Code)," National Aeronautics and Space Administration Technical Memorandum, 4724, August 1996.

13. Sleight, W. D., Knight, F. N., Jr., and Wang, T. J., "Evaluation of a Progressive Failure Analysis Methodology for Laminated Composite Structures," Proceedings of the AIAA/ASME/ASCE/AHS/ASC 38th Structures, Structural Dynamics, and Materials Conference, April 7-10, Kissimmee, FL, AIAA paper No. 97-1187, pp. 2257-2272, 1997.

14. Wang, T. W., Lotts, G. C., Sleight, W. D., "Analysis of Discrete-Source Damage Progression in a Tensile Stiffened Composite Panel," Proceedings of the AIAA/ASME/ASCE/AHS/ASC 40th Structures, Structural Dynamics, and Materials Conference, April 12-15, St. Louis, MO, AIAA paper No. 99-1336, 1999.

15. McGowan, M. D., Davila G. C., Ambur, R. D., "Damage Progression in BuckleResistant Notched Composite Plates Loaded in Uniaxial Compression," Proceedings of the AIAA/ASME/ASCE/AHS/ASC $42^{\text {nd }}$ Structures, Structural Dynamics \& Materials Conference, April 16-19, Seattle, WA, AIAA paper No. 2001-1482, 2001.

16. Baker J. D., "Failure Analysis of Discrete Damaged Tailored Extension-ShearCoupled Stiffened Composite Panels," Proceedings of the AIAA/ASME/ASCE/AHS/ASC $46^{\text {th }}$ Structures, Structural Dynamics \& Materials Conference, April 18-21, Austin, TX, AIAA paper No. 2005-2367, 2005.

17. Brogan, F.A., Rankin, C. C., and Cabiness, H. D., "STAGS Users Manual," Lockheed Palo Alto Research Laboratory, Report LNSC P032594, 1994. 
18. Qing, X, Chang, F.K., Starnes, J., "Damage Tolerance of Notched Composite Laminates with Reinforcing Strips," Journal of Composite Materials, Vol. 37, No. 02, 2003.

19. Tay, T. E., Liu, G., Tan, V. B. C., "Damage Propagation in Open-hole tension Laminates by the SIFT-EFM Approach," Journal of Composite Materials, Vol. 00, No. 00, 2005.

20. ABAQUS User's Manual, Vol. 1-3, Version 6.5, Hibbitt, Karlsson, and Sorensen, Pawtucket, RI, 2003.

21. Bathe, Klaus-Jurgen, Prentice-Hall, Inc., "Finite Element Procedures", pp. 824-828, 1996.

22. Knight, N.F. Jr, Rankin, C.C. and Brogan, F. A., "Controlling Progressive Failure Analyses using Artificial Viscous Damping," Proceedings of the AIAA/ASME/ASCE/AHS/ASC $42^{\text {nd }}$ Structures, Structural Dynamics \& Materials Conference, April 16-19, Seattle, WA, AIAA paper No. 2001-14181, 2001.

23. Helm, J. D., "Improved Three-Dimensional Image Correlation for Surface Displacement Measurement", Optical Engineering, Vol. 35, pp. 1911-1920, 1996.

24. Coats, W. T., Harris, E. C., "A Progressive Damage Methodology for Residual Strength Predictions of Notched Composite Panels," Journal of Composite Materials, Vol. 33, No.23, 1999, pp. 2193-2224. 
Table 1. Degradation model for ABAQUS/Explicit VUMAT

\begin{tabular}{ll}
\hline \hline Damage mode & Stresses set to zero \\
\hline Fiber failure in tension and compression & All stresses \\
Matrix cracking in tension, compression and & $\sigma_{22,} \tau_{12}$ \\
shear &
\end{tabular}

Table 2. Degradation model for ABAQUS/Standard USDFLD

\begin{tabular}{ll}
\hline \hline Damage mode & Properties Degraded \\
\hline Fiber failure in tension and compression & $\mathrm{E}_{11}, \mathrm{E}_{22}, \mathrm{G}_{12}, v_{12}$ \\
Matrix cracking in tension, compression and & $\mathrm{E}_{22}, \mathrm{G}_{12}, v_{12}$ \\
shear &
\end{tabular}

Table 3. Material properties and strength data

\begin{tabular}{lll}
\hline \hline Properties & $\begin{array}{c}\text { T800/3900-2 } \\
\left(\mathrm{X} \mathrm{10} 10^{6} \mathrm{psi}\right)\end{array}$ & \multicolumn{1}{c}{ Description } \\
\hline $\mathrm{E}_{11}$ & 23.2 & Young's modulus in fiber direction \\
$\mathrm{E}_{22}$ & 1.3 & Young modulus in the transverse direction \\
$\mathrm{G}_{12}$ & 0.9 & In-plane shear modulus \\
$\mathrm{X}_{\mathrm{t}}$ & 0.412 & Tensile strength in the fiber direction \\
$\mathrm{X}_{\mathrm{c}}$ & 0.225 & Compressive strength in the fiber direction \\
$\mathrm{Y}_{\mathrm{t}}$ & 0.00872 & Tensile strength in the transverse direction \\
$\mathrm{Y}_{\mathrm{c}}$ & 0.0243 & Compressive strength in the transverse direction \\
$\mathrm{S}_{12}$ & 0.01376 & In-plane shear strength \\
$V_{12}$ & 0.28 & Poission's Ratio \\
\hline \hline
\end{tabular}

Table 4. Specimen Specifications

\begin{tabular}{ccll}
\hline \hline ID & $\begin{array}{c}\text { Ply Percentages } \\
{[0 \text { 's/45's/90's }]}\end{array}$ & Laminate Stacking Sequence & $\begin{array}{c}\text { Thickness } \\
\text { (inches) }\end{array}$ \\
\hline Laminate 1 & {$[100 \% / 0 \% / 0 \%]$} & {$\left[0_{12}\right]$} & 0.078 \\
Laminate 2 & {$[40 \% / 40 \% / 20 \%]$} & {$[45 / 0 /-45 / 0 / 90]_{\mathrm{s}}$} & 0.065 \\
Laminate 3 & {$[58 \% / 28 \% / 14 \%]$} & {$\left[45 / 0_{2} /-45 / 0_{2} / 90\right]_{\mathrm{s}}$} & 0.091
\end{tabular}

Table 5. Failure Load

\begin{tabular}{cllll}
\hline \hline ID & ABAQUS/Standard & ABAQUS/Explicit & Experiment & Type of Failure load \\
\hline Laminate 1 & $9472 \mathrm{lbs}(8.8 \%)$ & $9182 \mathrm{lbs}(5.9 \%)$ & $8635 \mathrm{lbs}$ & Splitting load \\
Laminate 2 & $13071 \mathrm{lbs}(3.4 \%)$ & $13240 \mathrm{lbs}(4.6 \%)$ & $12632 \mathrm{lbs}$ & Ultimate failure load \\
Laminate 3 & $18613 \mathrm{lbs}(19.5 \%)$ & $18105 \mathrm{lbs}(21.4 \%)$ & $25840 \mathrm{lbs}$ & Splitting load
\end{tabular}




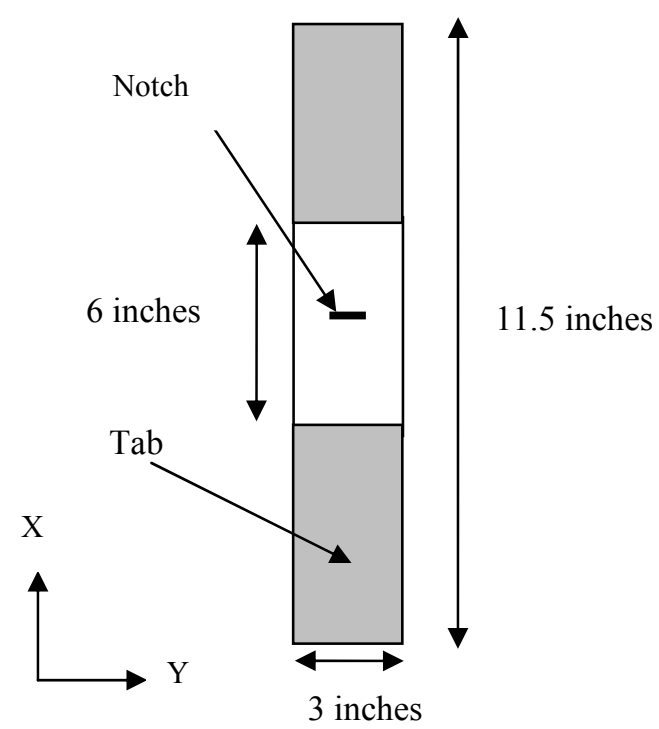

Figure 1. Center notched Tensile Specimen

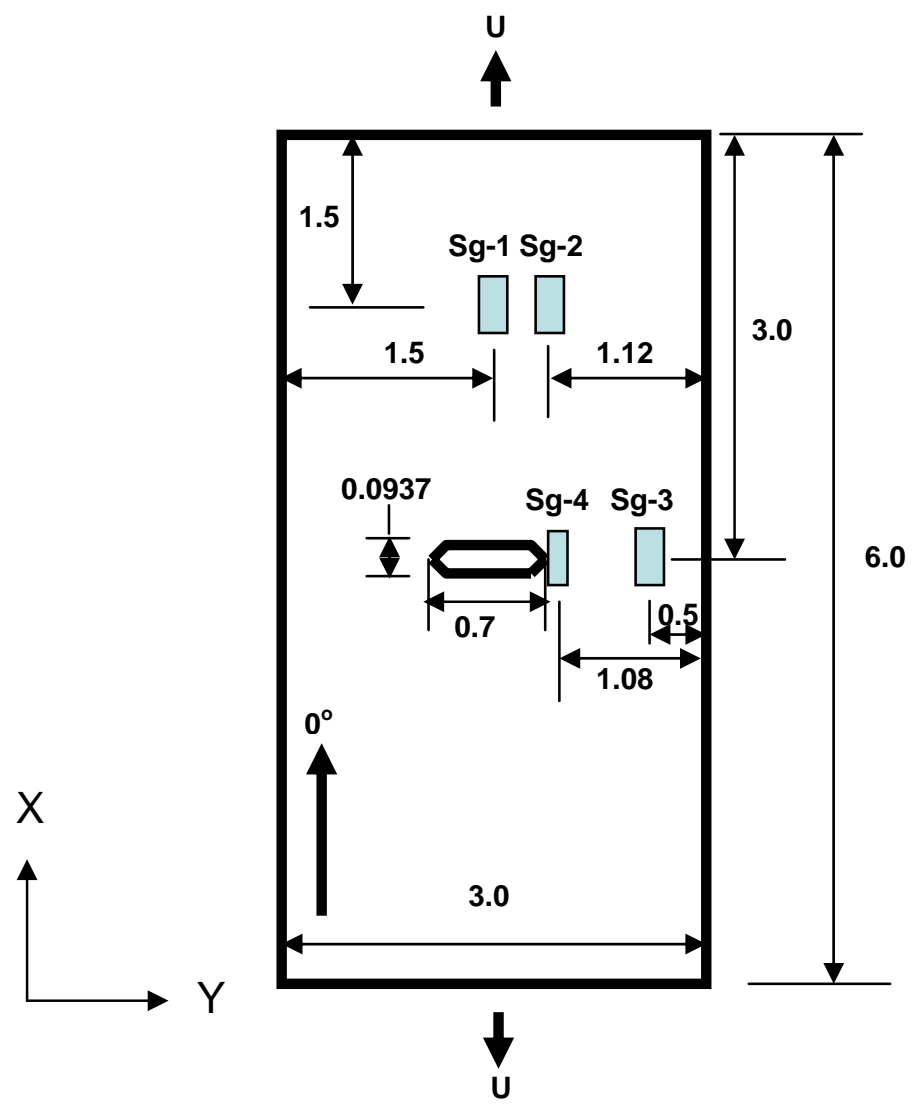

Figure 2. Strain gauge locations on the specimen 


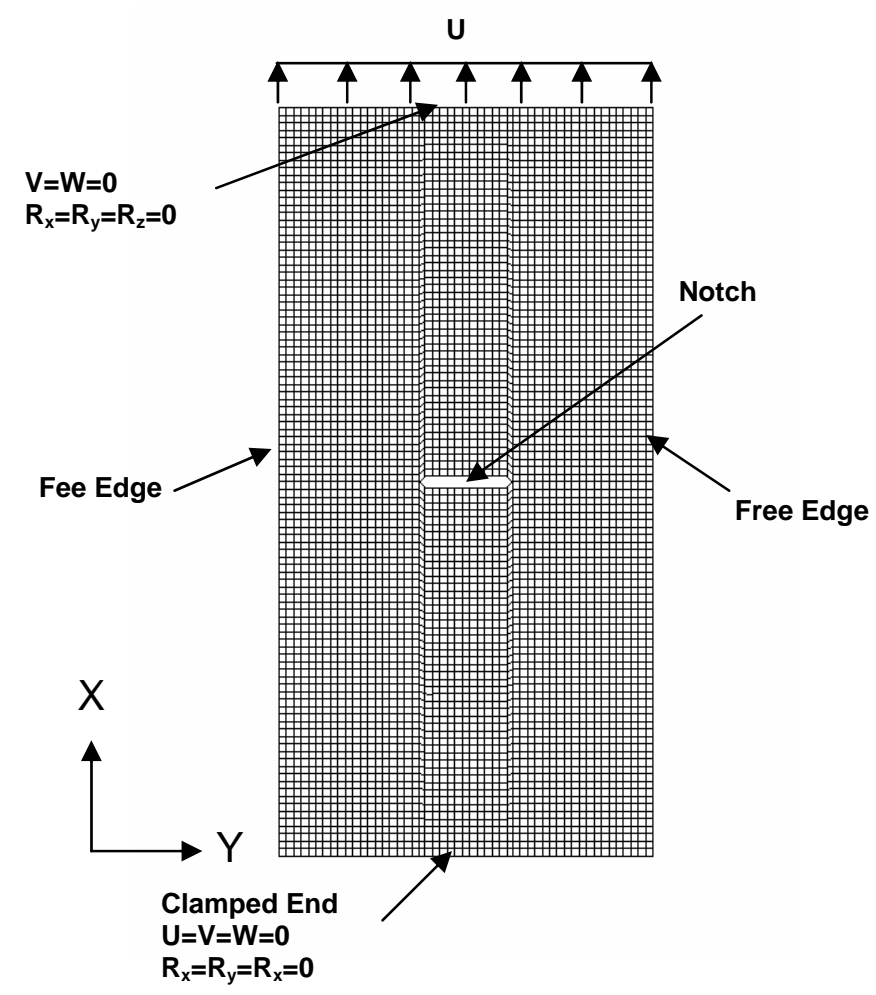

Figure 3. Finite Element Mesh

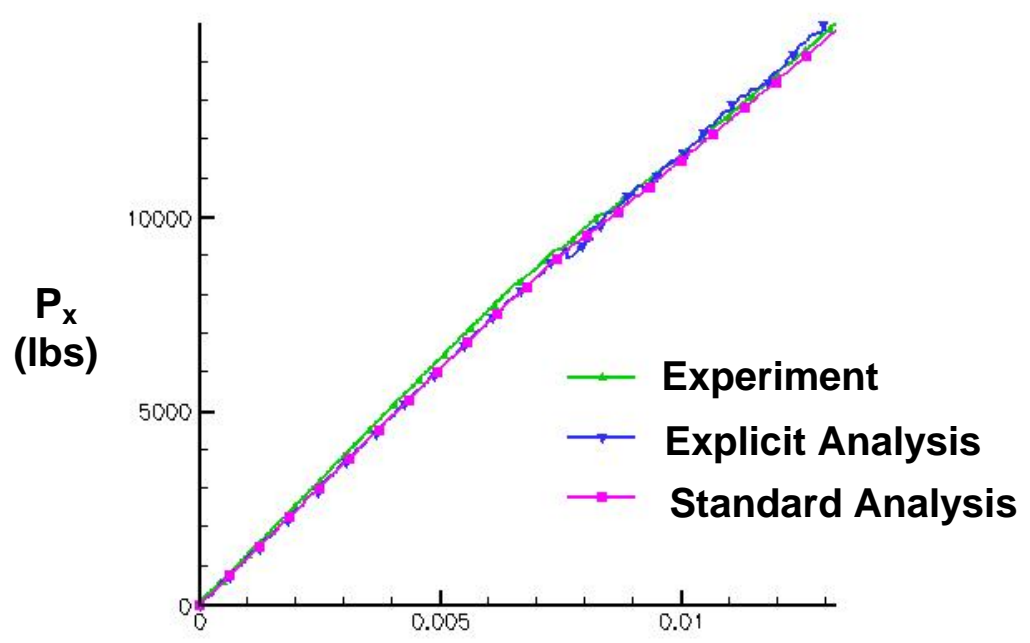

Elongation, $\Delta_{x}$, of a 4-in. long section

Figure 4. Load vs. End elongation of Laminate Sequence-1 


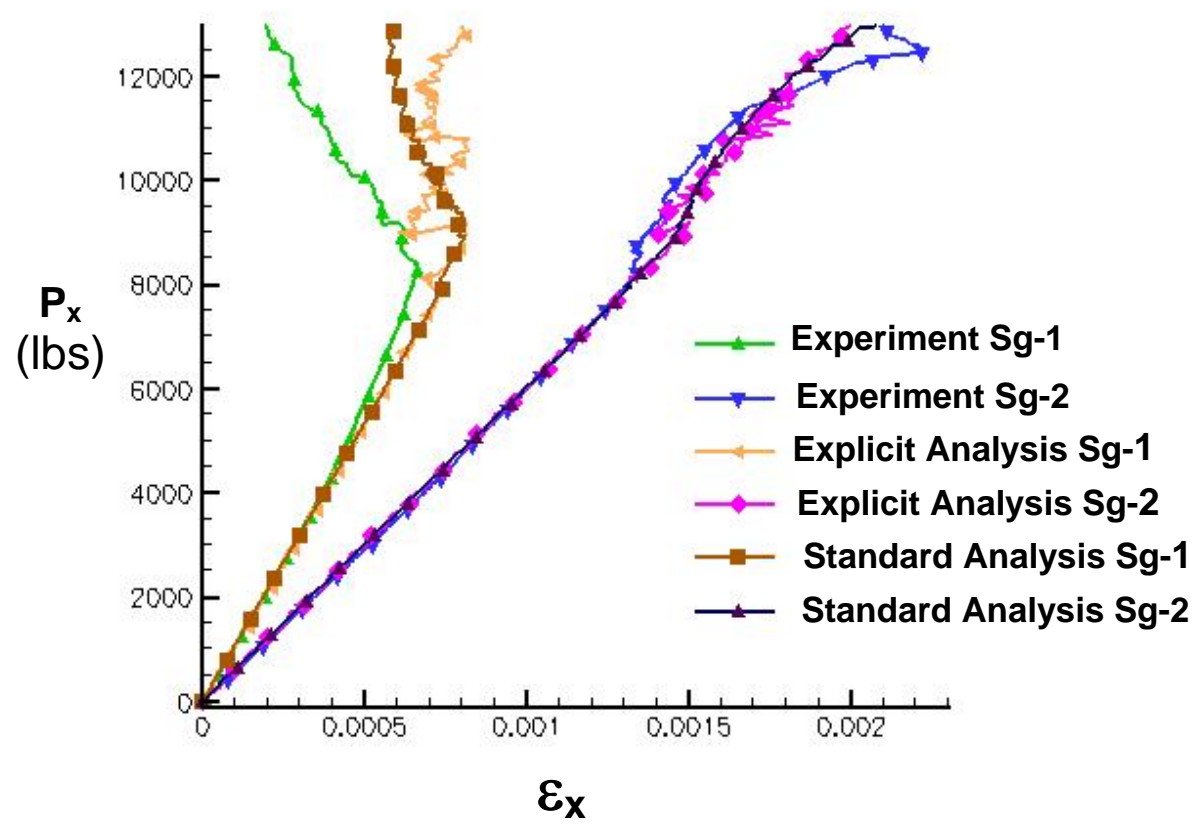

Figure 5. Load vs. strain in Laminate Sequence-1



Figure 6. Load vs. strain in Laminate Sequence-1 


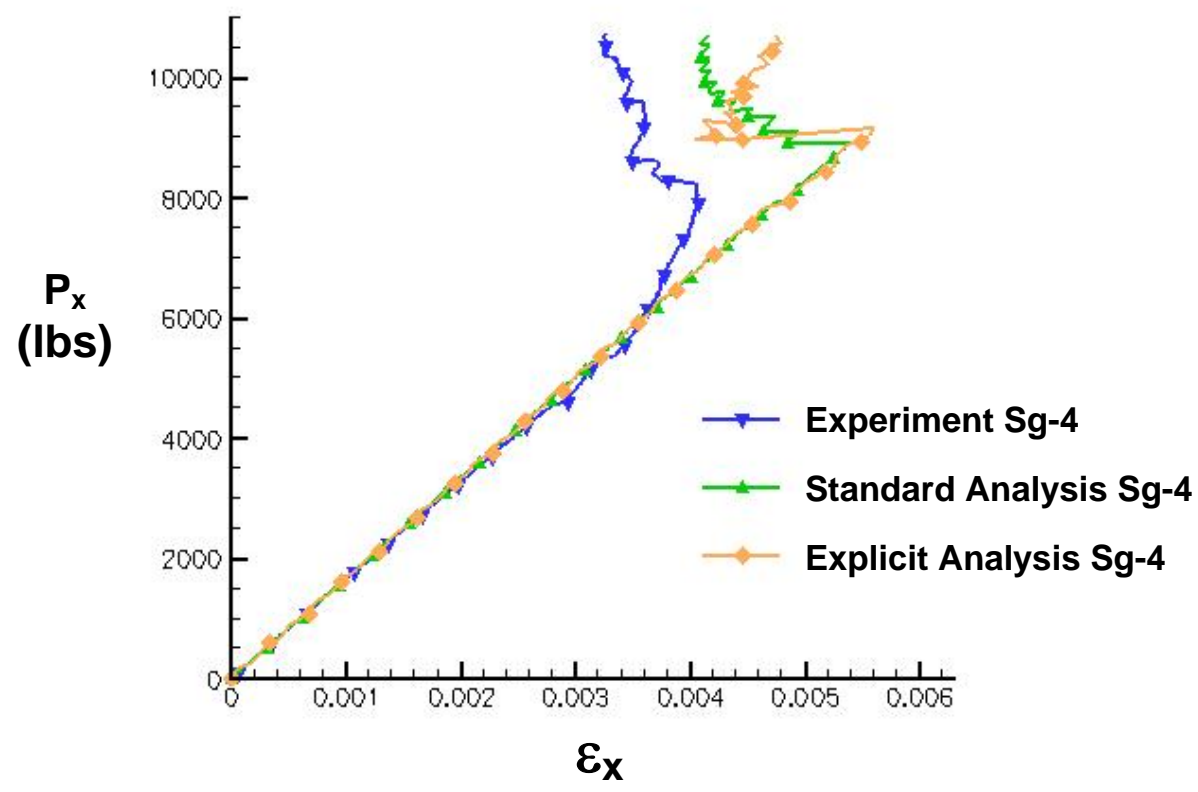

Figure 7. Load vs. strain in Laminate Sequence-1

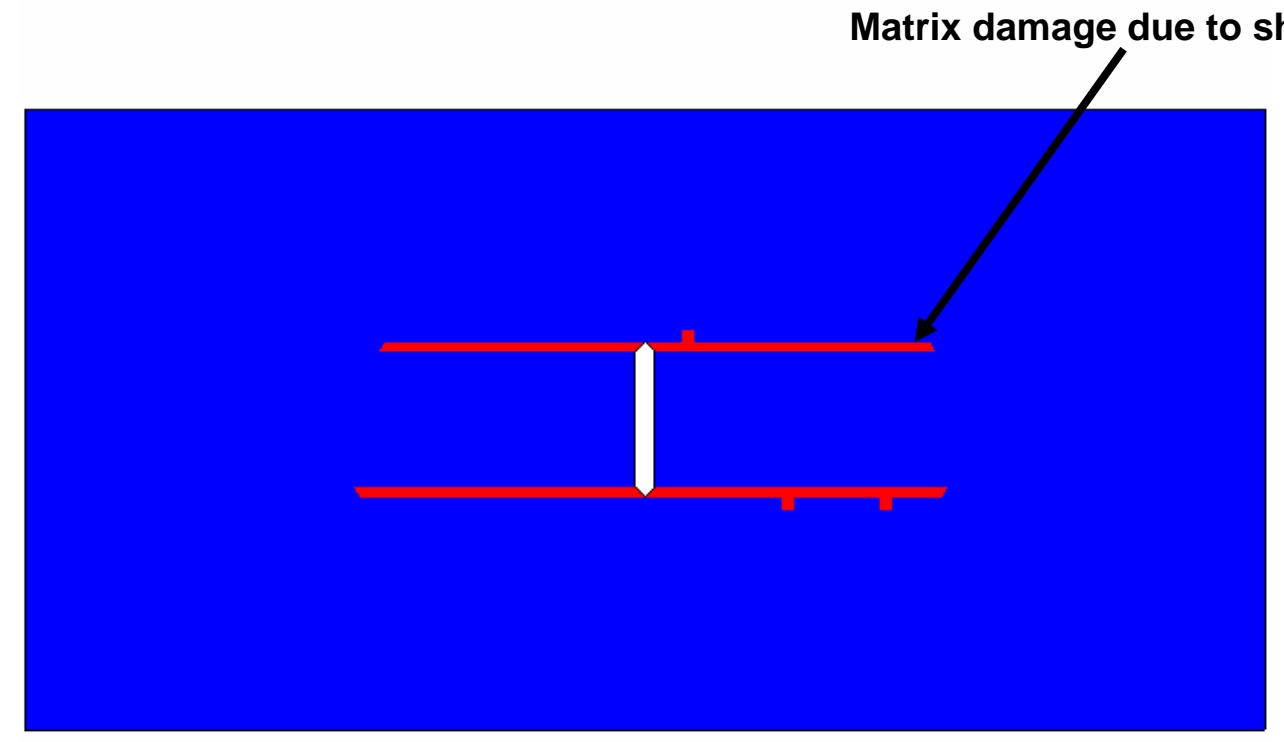

Figure 8. Damage path obtained from Abaqus/Explicit for Laminate Sequence-1 5 at $\mathrm{Px}=13342.15 \mathrm{lbs}$. 


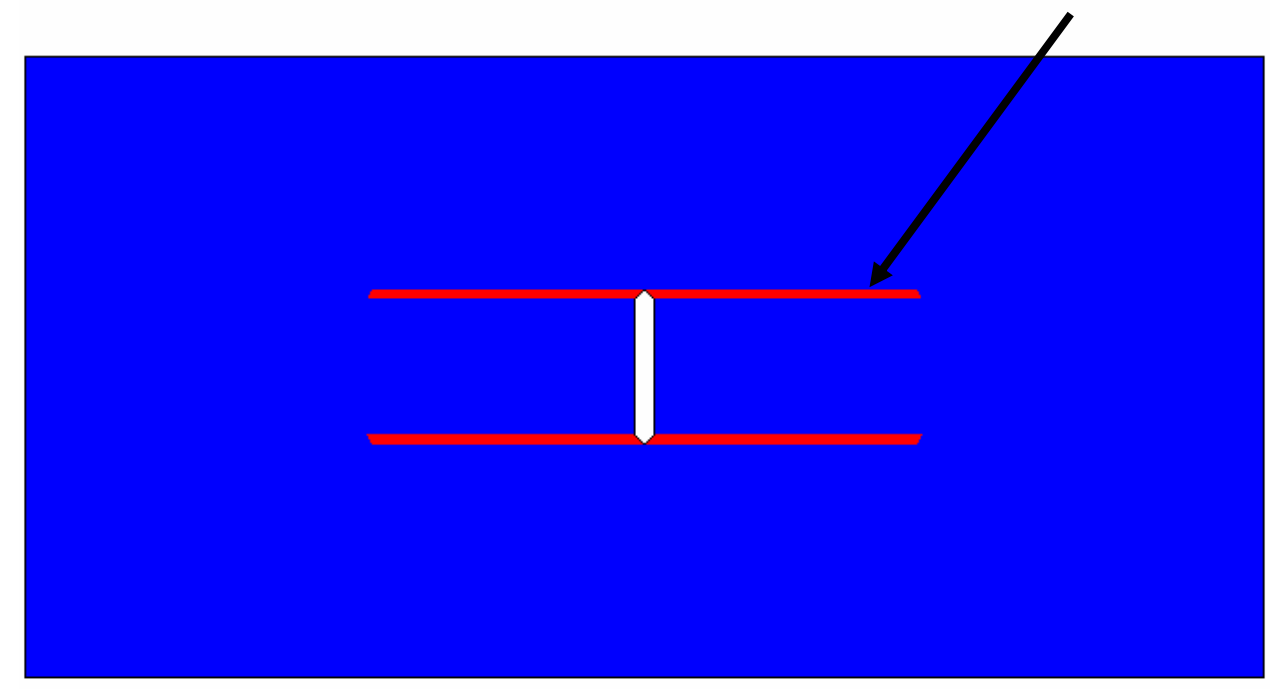

Figure 9. Damage path obtained from Abaqus/Standard of Laminate Sequence-1 at $P x=13465.0 \mathrm{lbs}$.

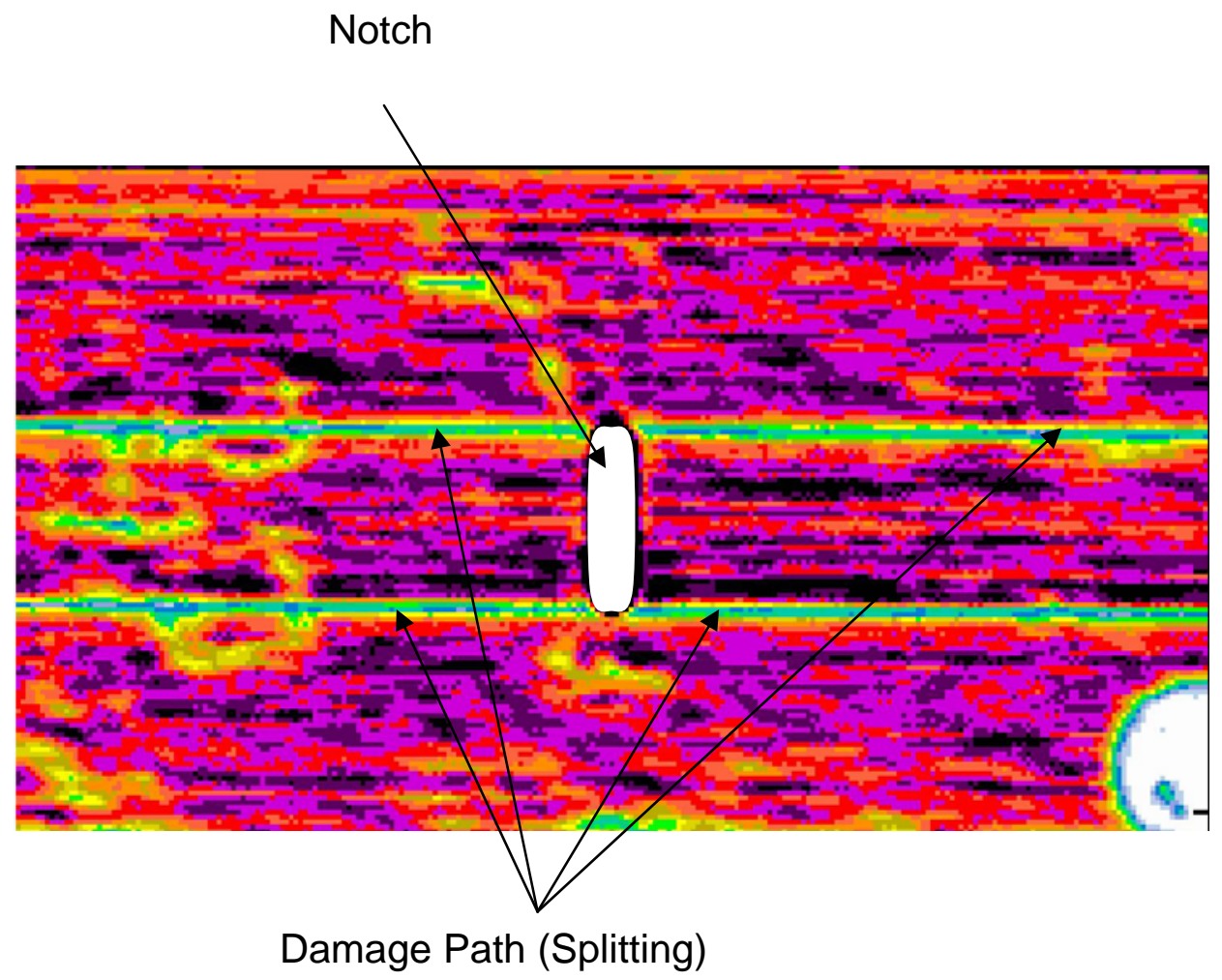

Figure 10. C-Scan picture of the damage in specimen of Laminate Sequence-1 


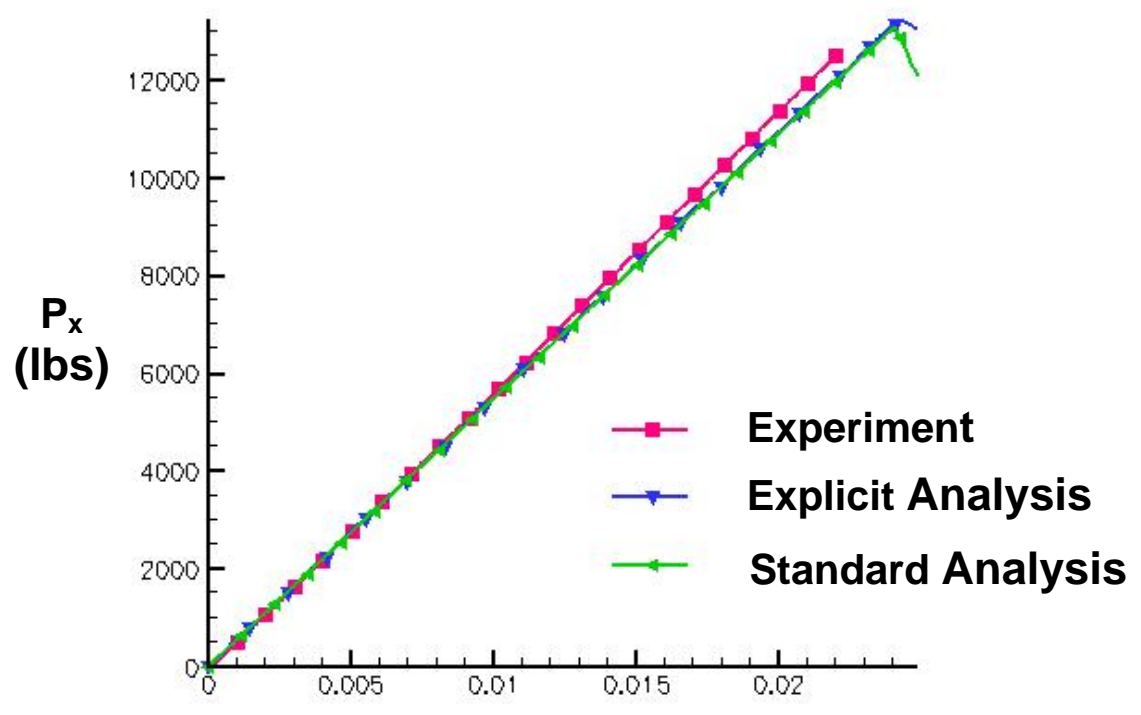

Elongation, $\Delta_{x}$, of a 4-in. long section

Figure 11. Load vs. End elongation of Laminate Sequence-2

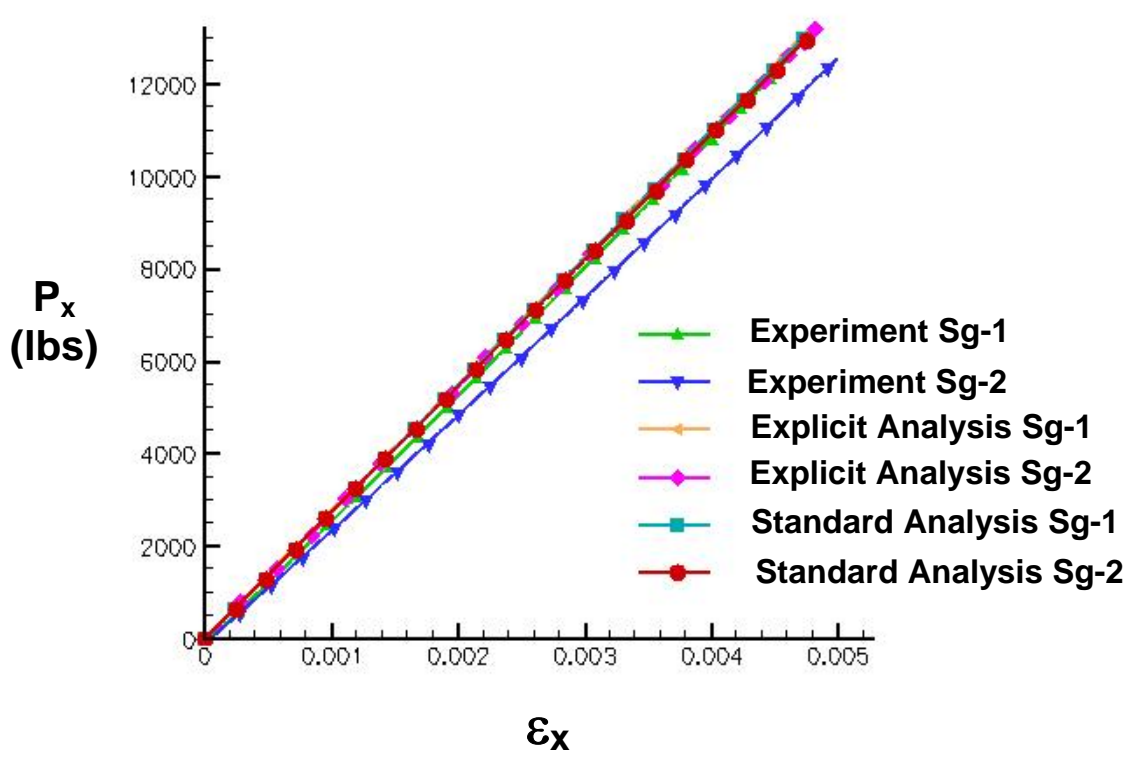

Figure 12. Load vs. strain in Laminate Sequence-2 




Figure 13. Load vs. strain in Laminate Sequence-2

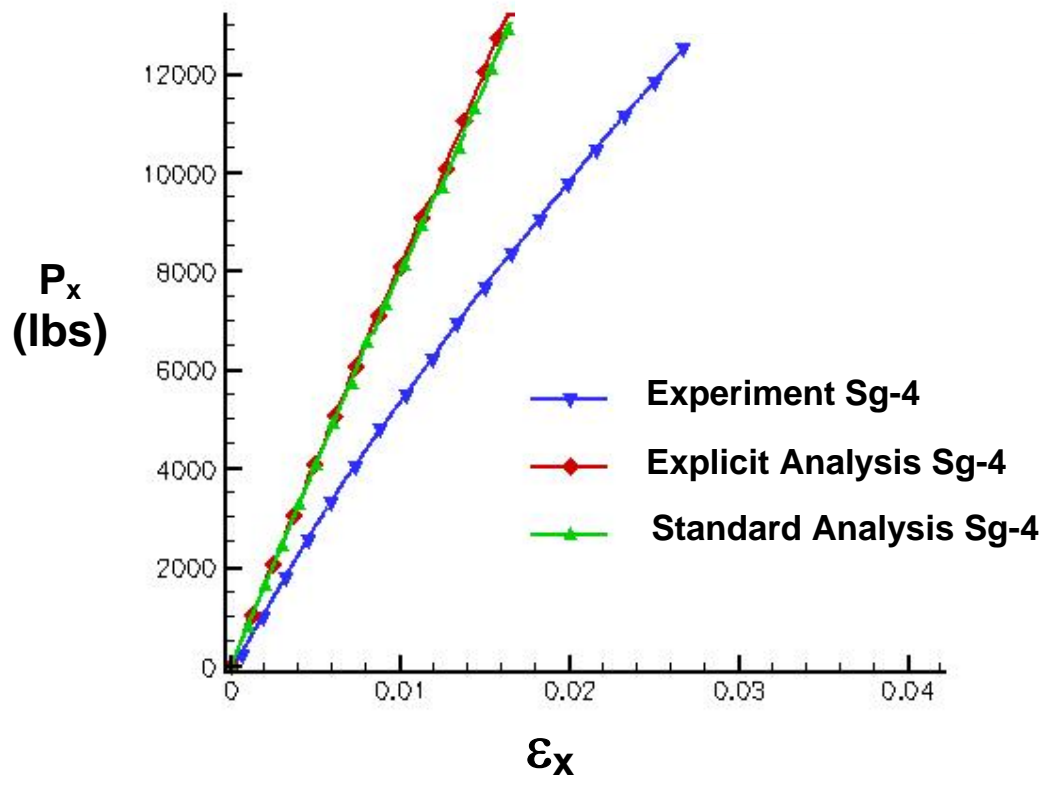

Figure 14. Load vs. strain in Laminate Sequence-2 


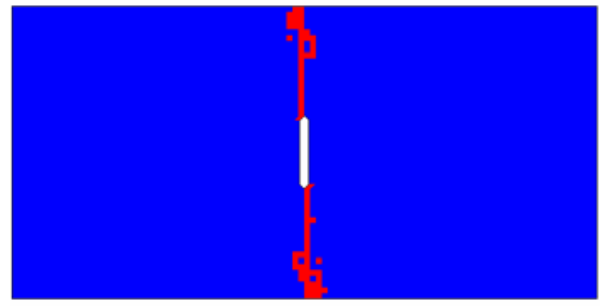

$45^{\circ}$ ply



$-45^{\circ}$ ply

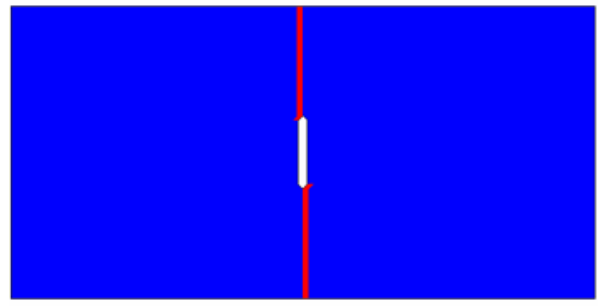

$$
0^{\circ} \text { ply }
$$

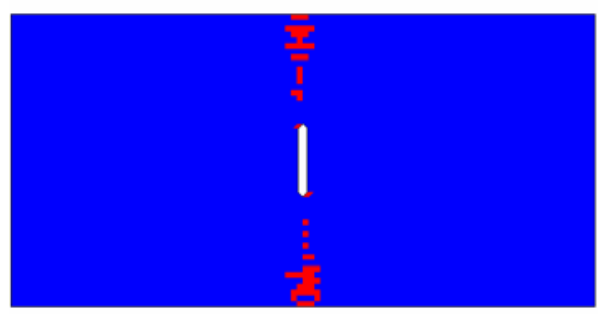

$$
90^{\circ} \text { ply }
$$

Figure 15. Damage path predictions by Abaqus/Explicit for Laminate Sequence-2 at $\mathrm{P}_{\mathrm{x}}=13240.0 \mathrm{lbs}$

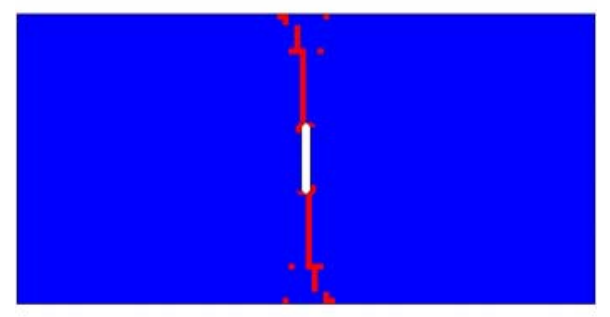

$45^{\circ}$ ply

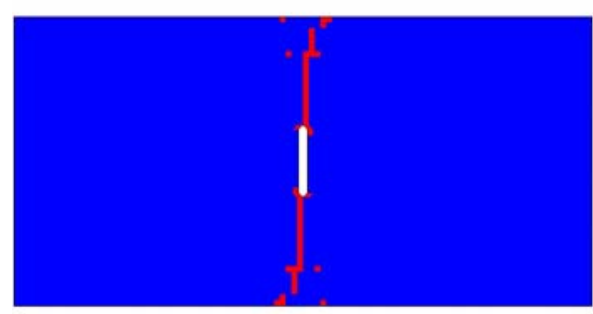

$-45^{\circ}$ ply

Fiber Failure 


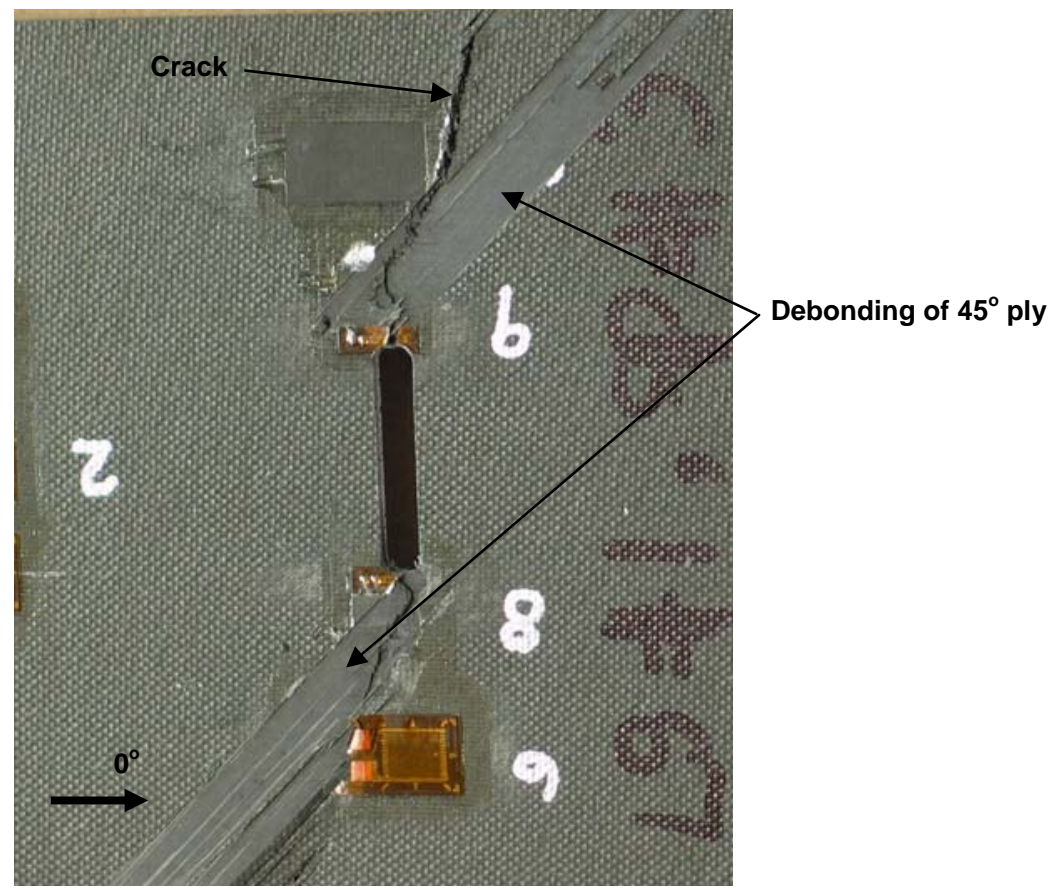

Figure 17. Damage in fail specimen of Laminate Sequence-2

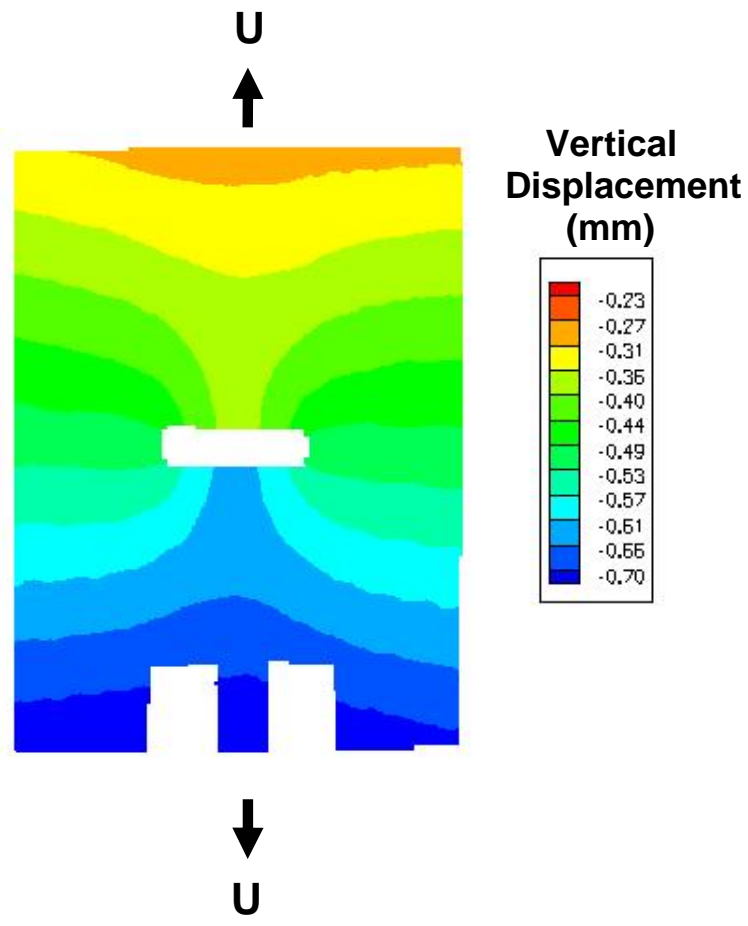

Figure 18. Vertical displacement of Laminate Sequence-2 obtained by VIC3D 


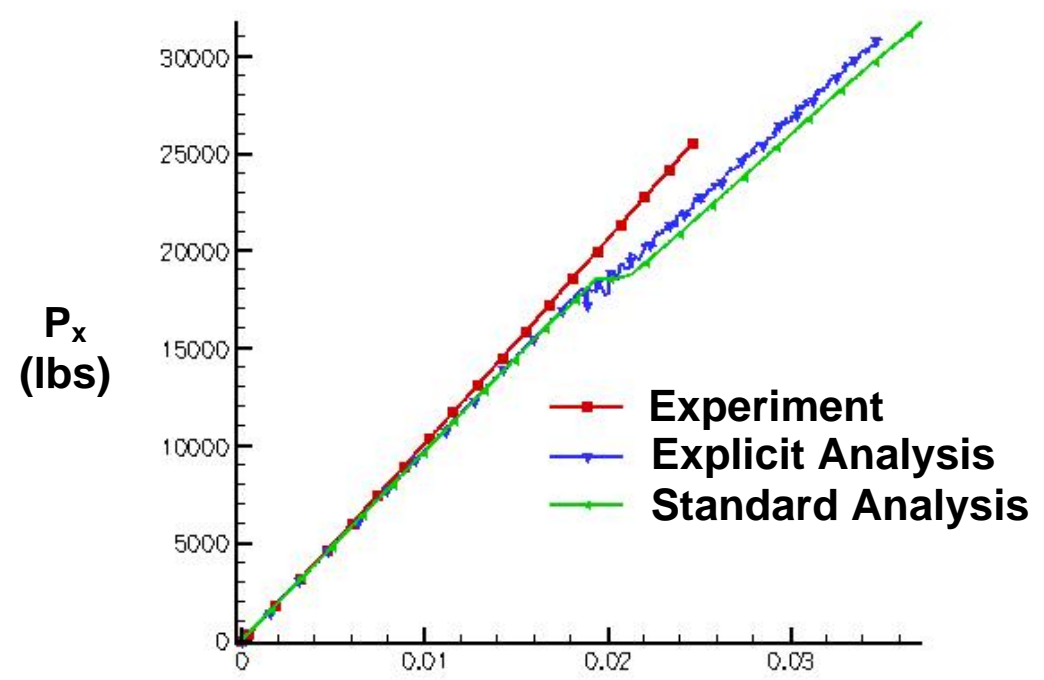

Elongation, $\Delta_{x}$, of a 4-in. long section

Figure 19. Load vs. End elongation of Laminate Sequence-3

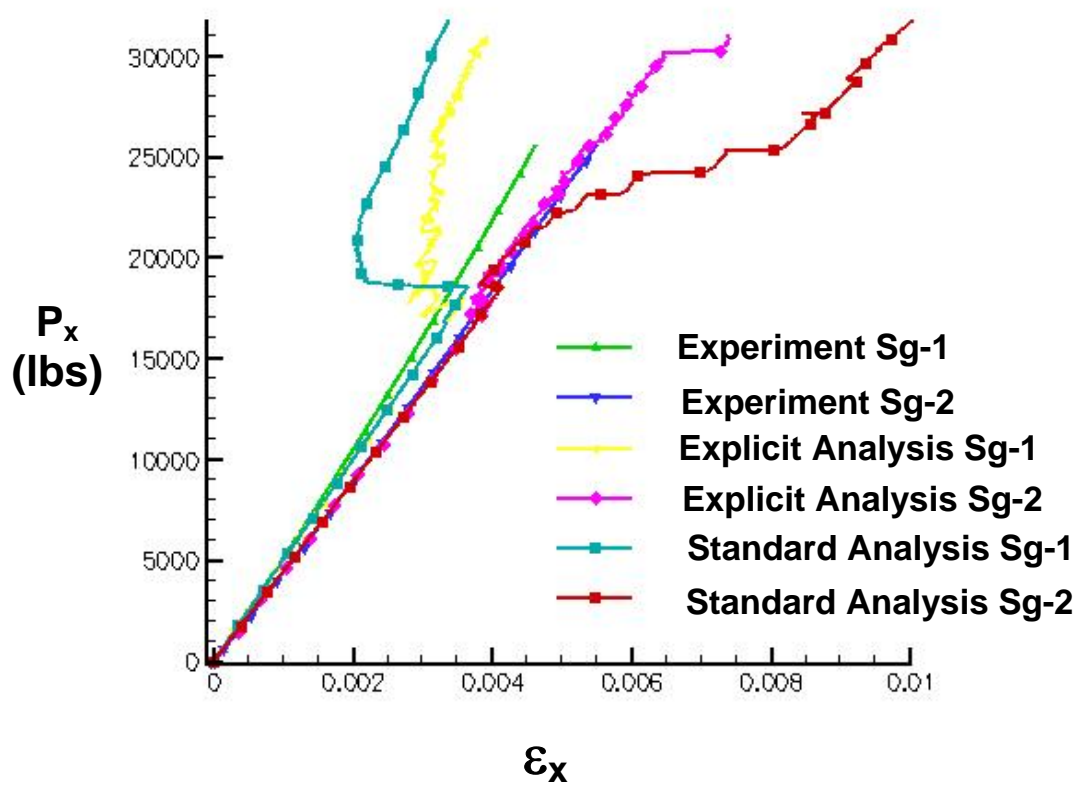

Figure 20. Load vs. strain in Laminate Sequence-3 


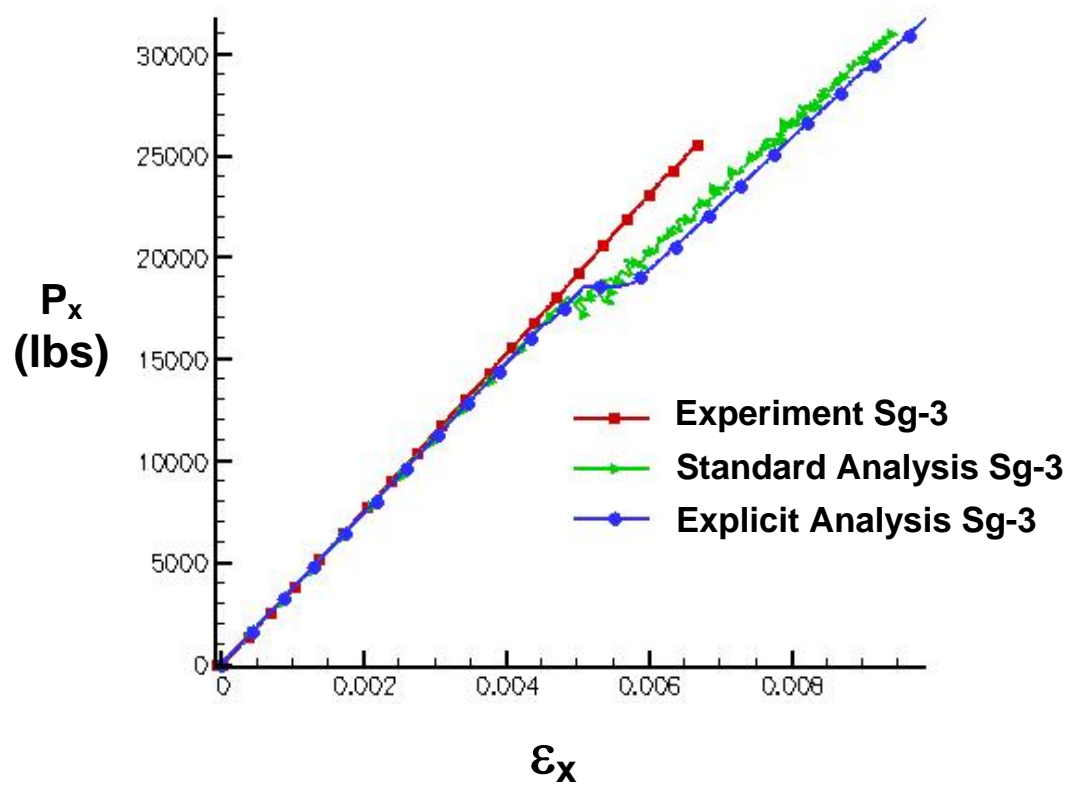

Figure 21. Load vs. strain in Laminate Sequence-3

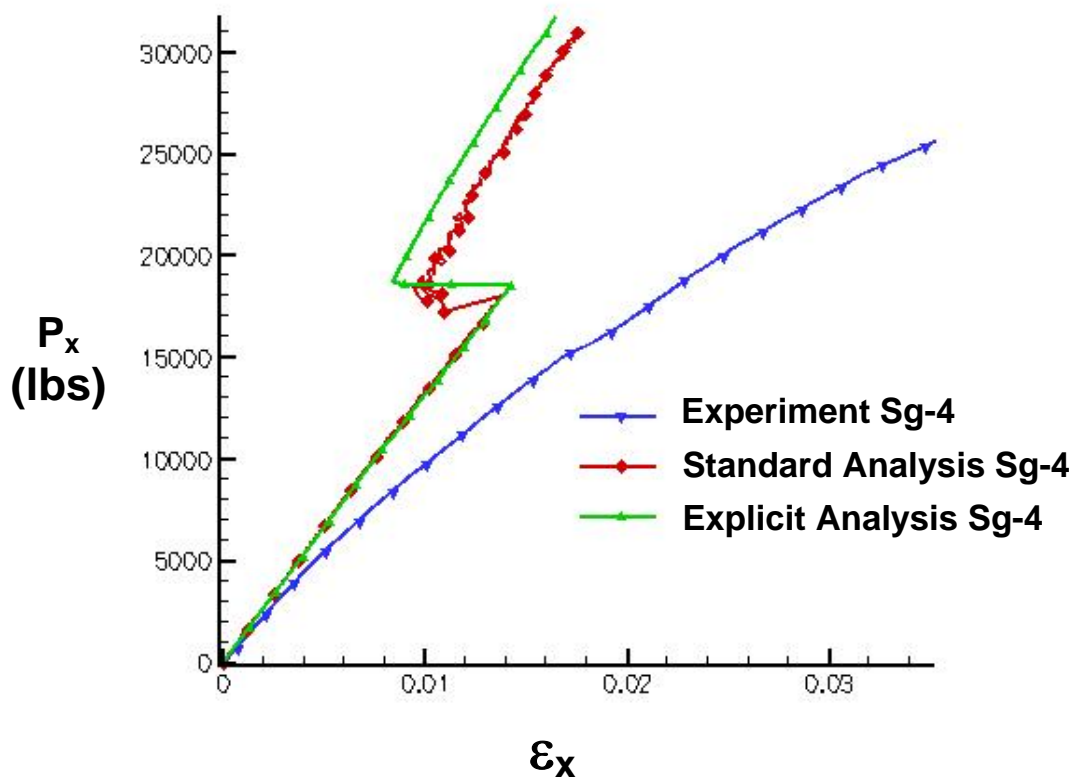

Figure 22. Load vs. strain in Laminate Sequence-3 


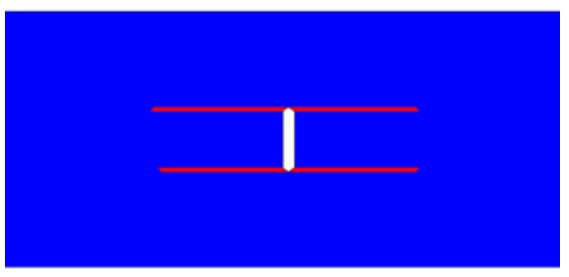

$45^{\circ}$ ply

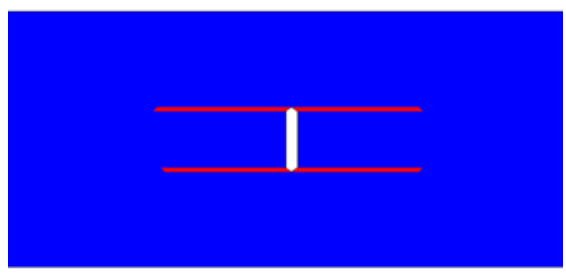

$$
-45^{\circ} \text { ply }
$$

\section{Fiber failure}

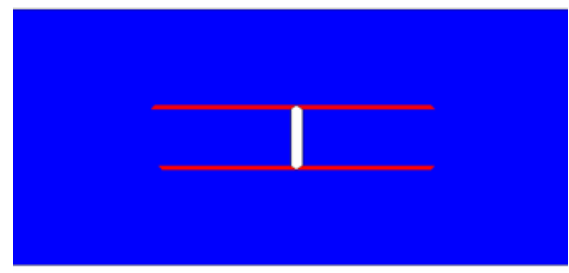

$$
0^{\circ} \text { ply }
$$

Matrix failure



$$
90^{\circ} \text { ply }
$$

Figure 23. Damage path predictions by Abaqus/Explicit for Laminate Sequence-3 at $\mathrm{P}_{\mathrm{x}}=26243.0 \mathrm{lbs}$.

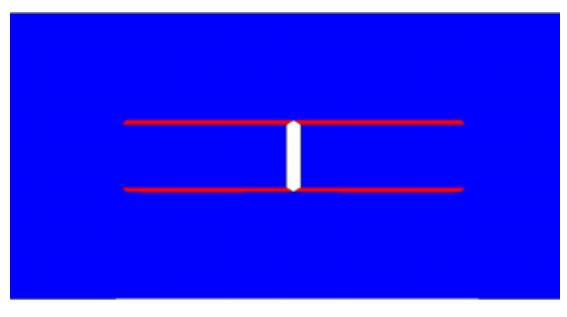

$45^{\circ}$ ply

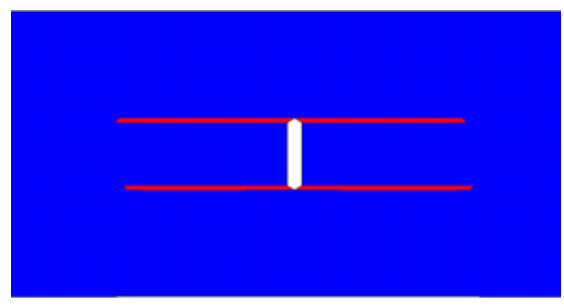

$0^{\circ}$ ply

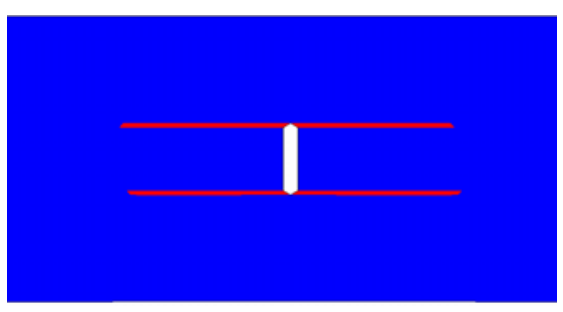

$-45^{\circ}$ ply

Fiber failure

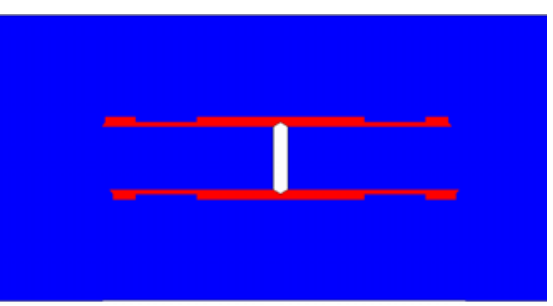

$90^{\circ}$ ply

\section{Matrix failure}

Figure 24. Damage path predictions by Abaqus/Standard for Laminate Sequence-3 at $\mathrm{P}_{\mathrm{x}}=26878.0 \mathrm{lbs}$ 




Figure 25. Actual Damage path (splitting) observed in specimen of Laminate Sequence-3

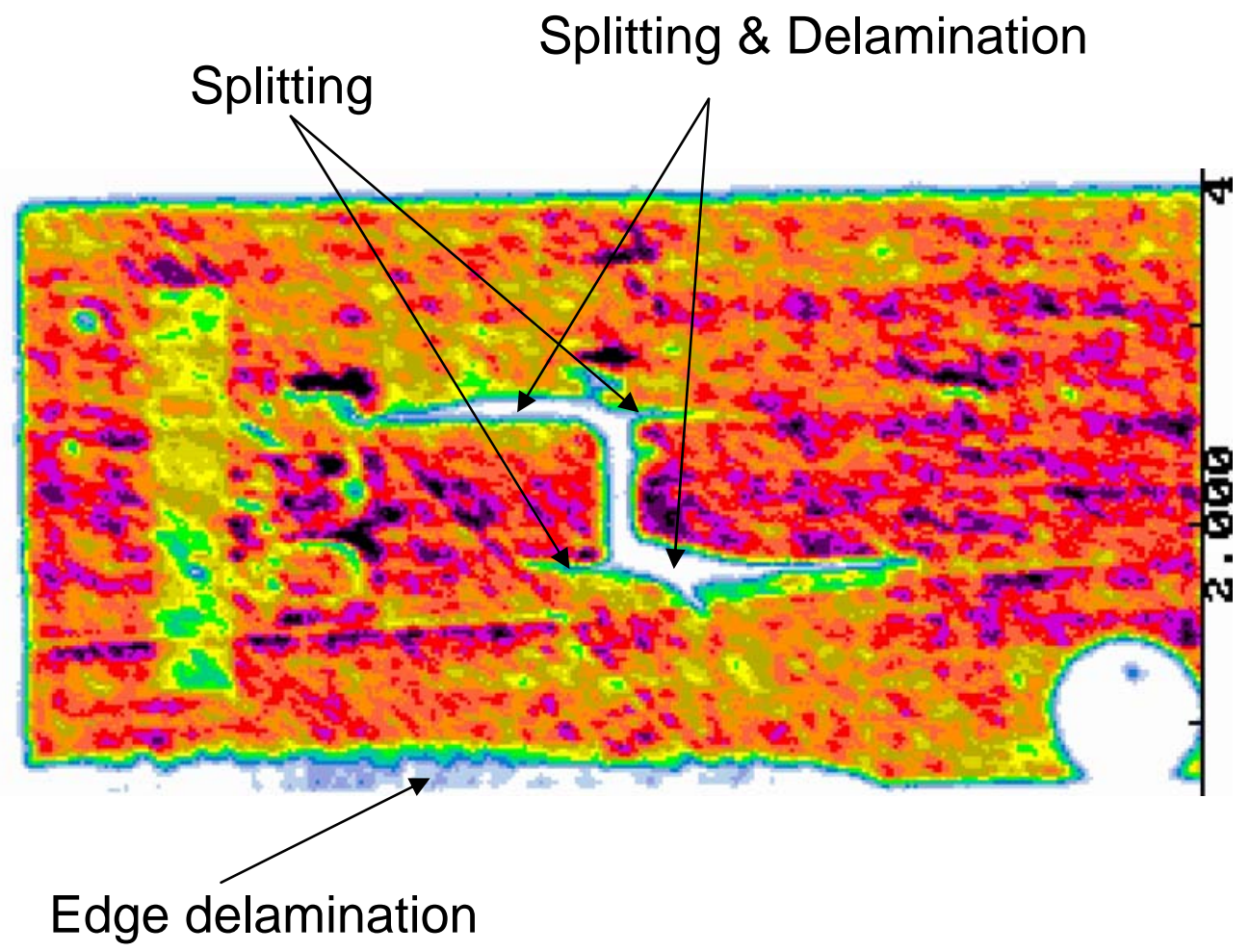

Figure 26. C-Scan picture of the damaged specimen of Laminate Sequence-3 


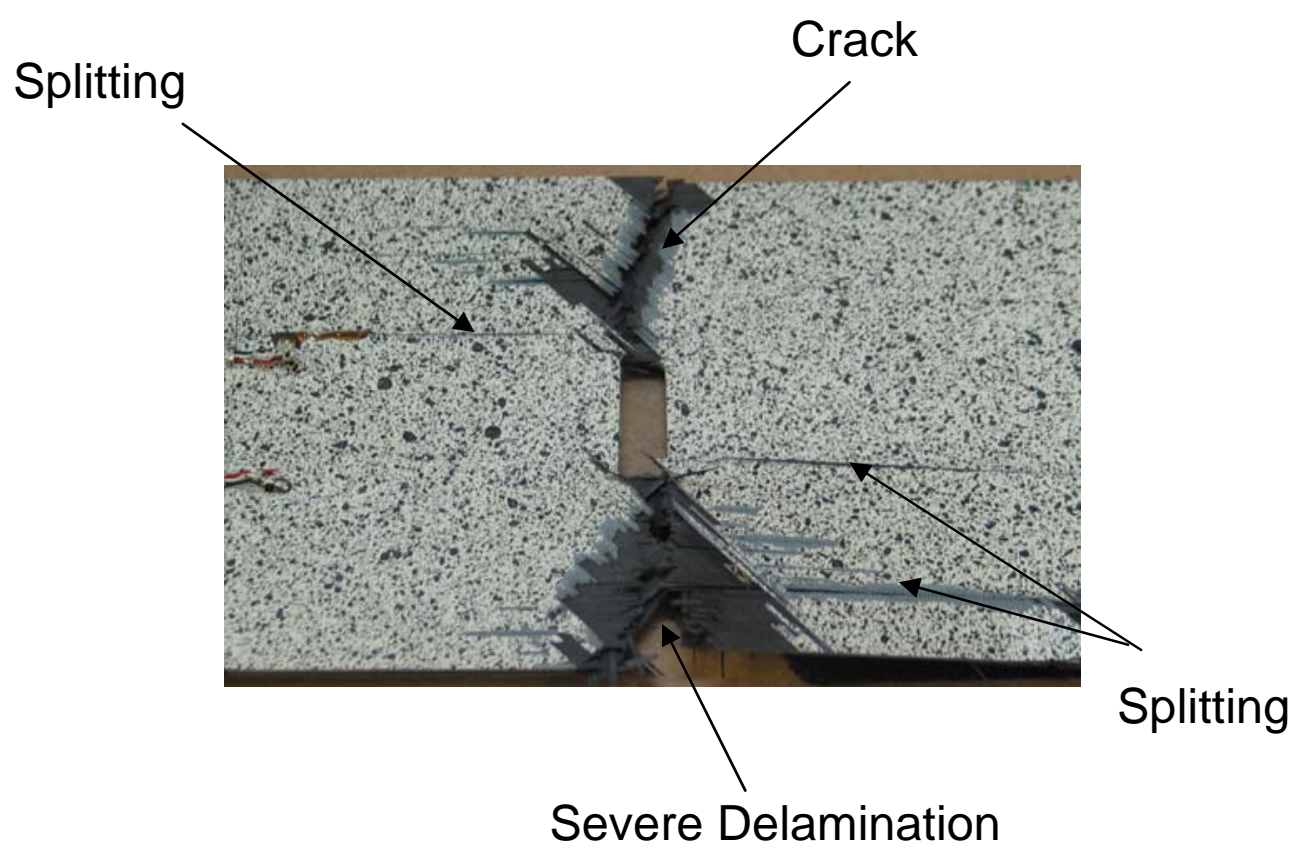

Figure 27. Actual damage in the specimen of Laminate Sequence-3



Figure 28. Vertical displacement of Laminate Sequence-3 obtained by VIC3D 